\title{
Church-driven primary health care: Models for an integrated church and community primary health care in Africa (a case study of the Salvation Army in East Africa)
}

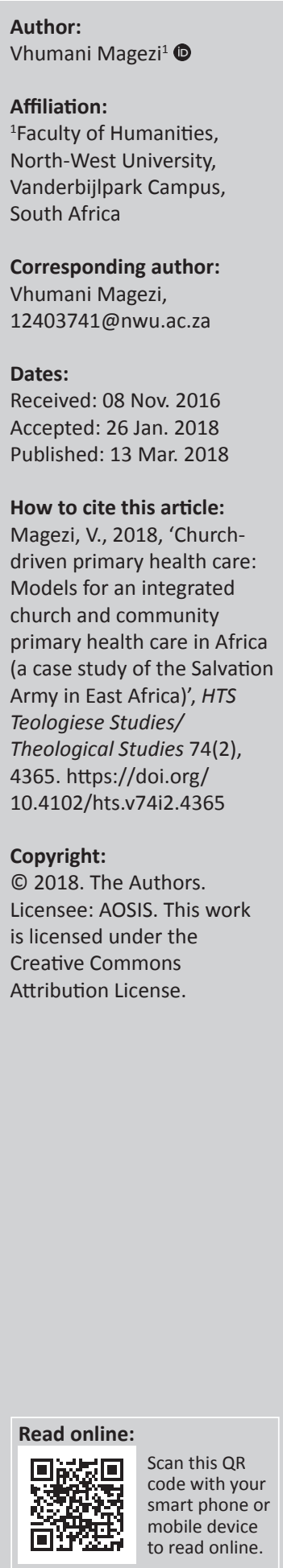

The role of churches in primary health care delivery in Africa's poor contexts is widely acknowledged. Discussion of churches' work in health largely focuses on the spiritual side and tends to downplay (or overlook) the practical side. A clear challenge and gap in the role of churches in primary health delivery is the lack of clear models and approaches to determine the efficacy of the interventions. Hence, the role of churches as a player in the delivery of primary health care needs examination. This paper examines the role of church-driven primary health care, using a practical case study of the health work of the Salvation Army in East Africa. It outlines the primary health services rendered by the Salvation Army and deduces five models that emerged from the work of the various implementing churches in delivering primary health care. The article proceeds from an analysis of the meaning of primary health care and how churches are historically and currently positioned to contribute to primary health care. The article demonstrates that, viewed from a primary health care delivery perspective, churches in Africa play a critical practical contribution further to a spiritual role. From a practical theology perspective, the paper provides insight into how churches could operate in communities within the interface of church and health spaces. However, the church's role and function is organic and differs in every community.

\section{Introduction and background}

Religion and religious institutions, particularly churches, play a critical role in health care in Africa. This role has been highly acknowledged and widely documented. Churches' contribution in health extends beyond psychological and spiritual care to practical health interventions (Babbel 2012; Dambisya \& Ichoku 2012; Foster 2010; Green et al. 2002; Magezi 2012; Samuels, Geibel \& Perry 2010; Zvobgo 1986). With the increased global focus on health, the role of churches in the delivery of primary health care (PHC) in communities should be examined. Churches' community participation role in delivering PHC should be assessed in order to discern emerging models being employed.

Ruger (2014:1) observed the increased focus on global health from two significant global developments: firstly, the appointment of Timothy Evans in July 2013 as the Director of Health, Nutrition and Population at the World Bank; and secondly, the nomination of Yong Kim, a global health expert, as president of the World Bank by President Obama. These developments, Ruger (2014) stated, indicate global health's ascendance in development practice, which puts global health in the spotlight. In these global health developments, Ruger (2014) observed that:

The World Bank learnt from past mistakes that top-down donor-driven development was both unfair and ineffective. With its poverty reduction strategy papers (PRSPs) and country assessment strategies, which take a country's 'own vision for its development' as the point of departure, the World Bank now seeks to serve countries in achieving their own goals. PRSPs aim to assist countries in meeting the Millennium Development Goals. (p. 2)

Framed within community development language, the lesson learnt by the World Bank indicates the need for a bottom-up approach, which entails country and community participation.

The focus on global health is also evidenced through WHO initiatives. The World Health Report (WHO 2008:13) noted international renewed focus on PHC as the engine for achieving global health outcomes. The report stated that:

Note: This article is published in the section Practical Theology of the Society for Practical Theology in South Africa. 
Global health is receiving unprecedented attention, with growing interest in united actions, greater calls for comprehensive and universal care - be it from people living with HIV and those concerned with providing treatment and care, Ministers of Health, or the Group of Eight (G8) - and a mushrooming of innovative global funding mechanisms related to global solidarity. There are clear and welcome signs of a desire to work together in building sustainable systems for health rather than relying on fragmented and piecemeal approaches. (WHO 2008:13)

Primary health care has been identified as an integral component in achieving global health outcomes. Hence, it is worthwhile to understand its elements and the various models that could be used to effectively implement it. PHC delivery is a combined effort of diverse actors and diverse disciplines (Thomas-MacLean et al. 2004). The principles that underlie it are access, equity, essentiality, appropriate technology, multi-sectoral collaboration and community participation and empowerment. With community participation as a critical component of $\mathrm{PHC}$, it is crucial to understand the dimensions and functions of communities in health delivery. Rodriguez-Garcia et al. (2013:4), in their 15 extensive evaluation studies across eight countries on the role of communities commissioned by the World Bank and Department for International Development DFID (now UK AID), described community responses by characterising them into six main categories:(1) types of implementing organisations and structures; (2) types of implemented activities or services and beneficiaries; (3) actors involved in and driving the response; (4) contextual factors influencing responses; (5) the extent of community involvement in the response; and (6) the extent of involvement of wider partnerships and collaborative efforts.

One structure responsible for implementing community interventions such as PHC in Africa is faith-based communities, particularly churches. Foster's (2010) study on HIV church interventions revealed that out of 671 churches surveyed in Namibia, Uganda and Sierra Leone, 53\% had church-based HIV initiatives. The World Bank (2014) report on Kenya noted vibrant faith-based organisations (FBOs), especially churches, that played a crucial role in health delivery. Churches are subsystems of communities that are critical in the delivery of health and HIV services in Africa (Magezi 2007; 2012). The World Council of Churches (2010) reported that the World Health Organization estimated that FBOs provide $30 \%-70 \%$ of health care in the developing world. Mati (2013) further observed that FBOs are the most prominent manifestations of civil society in Africa. He added that FBOs have been playing a key role in African development and this situation will continue for many years to come. However, Mati (2013) lamented the inadequate attention given to FBOs in social scientific analysis.

In their classification of community responses, RodriguezGarcia et al. (2013:4) identified churches as one of the main community implementing organisations and structures. Churches implement different types of activities and services.
It is imperative therefore, as Mati (2013) noted, to analyse the models and approaches employed by churches in implementing community interventions such as health interventions. To that end, the role of churches in PHC delivery is of particular interest. The question posed is: considering that churches as religious institutions are subsystems of communities that, amongst other things, are involved in the delivery of PHC, what kind of models are organically emerging from practical church-driven PHC interventions in the communities? This question poses a challenge to researchers to develop theories and models from real life programmes. The question is about implementation research. Magezi (2017:1) concurs with Peters et al. (2014:1) in their insightful article, 'Implementation research: What it is and how to do it'. Peters et al. (2014:1) rightly observed that implementation research is a growing but not well understood field'. Woolsey and Biebel (2007) described implementation research as 'a black box, providing information about the journey from research theory to actual practice. Implementation studies examine issues of design, administration, and operation by tracking day-to-day, "real world" events' (Woolsey \& Biebel 2007:3). Peters et al. (2014:3) suggest that, amongst other things, implementation research is to identify and describe the implementation dynamics and the practical models that emerge in a given real life context.

In response to this question, this article considers the practical role that churches in poor African contexts may play to strengthen their practical contribution to PHC beyond religious and spiritual contemplation. It does so through a case study analysis of church-driven PHC interventions implemented in three countries in the East African region by the Salvation Army. PHC includes aspects such as disease prevention and health promotion, which are largely performed by churches or church volunteers in Africa (Foster 2010). This means when churches take a lead in implementing PHC related activities, it can rightly be deemed a church-driven PHC process. The three countries where the interventions were implemented are Kenya, Tanzania and Uganda. A case study, which is the research approach employed, is a research strategy that focuses on an empirical inquiry that investigates a phenomenon within its real context. In a qualitative study, a case study refers:

to the in depth analysis of a single or small number of units. A case study unit may include a single person, a group of people, an organisation or an institution. (University of Surrey n.d.:1)

Therefore, within this paper, the case study refers to the sites examined across the three countries of Kenya, Tanzania and Uganda.

Importantly, the programme being examined was not designed as an academic research project but a church health programme. However, it is worth examining from a practical inquiry perspective as implementation research. Magezi (2017:4) explained that a practical inquiry approach is rooted in pragmatist philosophy. It aims at generating knowledge for local people as well as general practice. Göran (n.d.) 
explained that while a practical inquiry approach shares similarities with action research, there are differences. He further elaborated that the purpose of a practical inquiry is, through empirical study on practical matters in local practices, to contribute to general practical knowledge. Stevenson (2005) contrasted practical inquiry with positivist inquiry approaches by noting that positivist approaches produce theories that are detached from the practical situations of people and lack relevancy to everyday practice; practical inquiry, on the other hand, generates practical knowledge in the fluidity and flux of practical daily realities. He added that practical theory is judged in terms of whether or not it helps people to 'go on' with their lives.

The purpose of this article is, through an inductive approach, to discern models that pragmatically emerged from the practical work of the various implementing churches that were delivering PHC services in the three countries (Kenya, Tanzania and Uganda). The primary health services rendered by the Salvation Army in the three countries are described $^{1}$ and categorised into inductive cluster models. Thus, this article sheds light on the practical dynamics of church health programmes, which contributes to developing theoretical understanding of church programmes. In doing so, the article answers the question: what models organically emerge from practical church-driven PHC interventions in the communities - that is, based on the East African region of the Salvation Army? The next section discusses the understanding of PHC role and position as well as the contribution of churches in PHC.

\section{Churches in communities and participation in primary health care Community participation in primary health care}

Thomas-MacLean et al. (2004), Magawa (2012), Marafa (n.d.) and many other health researchers, drawing from Alma-Ata (WHO 1978), defined PHC as processes and beliefs about the ways in which health care is structured. It includes primary care, disease prevention, health promotion, population health and community development within a holistic framework. This is done to provide essential community-focused health care. Marafa (n.d.) concisely described PHC as:

Essential care based on practical, scientifically sound and socially acceptable method and technology made universally accessible to individuals and families in the community through their full participation and at a cost they, and the country can afford to maintain in the spirit of self-reliance and selfdetermination:

- Primary health care reflects and evolves from the economic conditions and sociocultural and political characteristics of the country and its communities.

- Addresses the main health problems in the community providing promotive, preventive, curative and rehabilitative services.

1.The article employs a descriptive analysis through describing and categorising phenomena.
- It includes education concerning the prevailing health problems and the methods of preventing and controlling them.

- It involves, in addition to the health sector, all related sectors and aspects of national and community development, for example, agriculture, education, housing, etc. (p. 1)

Thomas-MacLean et al. (2004:1) added that PHC acknowledges the role of health care providers from diverse disciplines, within a philosophy and framework guided by the principles of access, equity, essentiality, appropriate technology, multi-sectoral collaboration and community participation and empowerment. Each discipline contributes to health and health services in a unique way and through collaborative interdisciplinary practice. Health care is provided within people's environment as well as their historical, sociopolitical, economic and cultural contexts.

Tarlier, Johnson and Whyte (2003:2) clarified that while primary care is a constituent and an integral component of PHC, the two are distinct. Primary care is the first level of contact of individuals and families within the national health system. It brings health care as close as possible to where people live and work. Vukic and Keddy (2002) importantly stated that PHC forms an integral part of a country's health system. They noted that while:

the main focus of primary health care is the health of individuals, families and communities; it is equally concerned with addressing the overall social and economic development of communities, thereby targeting the social determinants of health. (p. 545)

Community participation is a critical component of PHC. Different from a narrowly focused facility-based health delivery system, PHC utilises the community. Community participation includes individuals and families taking responsibility for their own health and that of the other community members. It also entails developing the capacity to contribute to community development. Participation can be in the area of identification of needs or during implementation. Communities participate at village, ward, district or local government levels.

The documented benefits of community participation as a development approach in health delivery include: addressing the real and felt health needs of the people, ensuring social responsibility amongst the community, sustainability of health delivery, cost sharing, enhancement of knowledge and intersectoral collaboration. The value of PHC was noted by Magawa (2012). She observed that 'countries with a well-functioning PHC system such as Cuba, Thailand, Brazil and Oman have better health outcomes at low costs' (Magawa 2012:3).

There has been renewed focus on PHC as spelt out in the Declaration of Alma-Ata on PHC made in 1978 (WHO 1978). The WHO Director-General responsible for PHC, Dr Margaret Chan, observed that while the global health context has changed remarkably over six decades since the establishment of WHO and three decades since the Alma-Ata Declaration (1978) on PHC, the values that lie at 
the core of the WHO Constitution and those that informed the Alma-Ata Declaration have been tested and remain true (WHO 2008:2). Therefore, in her director's message in the World Health Report (WHO 2008:2-3), she called on member states to revisit the vision of PHC. She recommended a shift towards more comprehensive thinking about the performance of the health system as a whole. She advised member states to narrow the intolerable gaps between aspiration and implementation. She further called attention to four reforms that reflect a convergence between the values of $\mathrm{PHC}$, the expectations of citizens and the common health performance challenges that cut across all contexts. These reforms include:

- universal coverage reforms that ensure that health systems contribute to health equity, social justice and the end of exclusion, primarily by moving towards universal access and social health protection

- service delivery reforms that reorganise health services around people's needs and expectations, so as to make them more socially relevant and more responsive to the changing world, while producing better outcomes

- public policy reforms that secure healthier communities, by integrating public health actions with primary care, by pursuing healthy public policies across sectors and by strengthening national and transnational public health interventions

- leadership reforms that replace disproportionate reliance on command and control on one hand, and laissez-faire disengagement of the state on the other, by the inclusive, participatory, negotiation-based leadership indicated by the complexity of contemporary health systems (WHO 2008:3).

These reforms have a clear veneer of community participation in providing PHC. This includes the need to reorganise health services around people's needs for relevance, secure health communities through integration of public health with primary health, participatory and negotiated processes in health leadership issues and addressing issues of social injustice and exclusion. This call places communities as critical and key contributors to PHC provision.

The WHO (2008) World Health Report asks an insightful question and provides a response that is relevant to our discussion:

Why a renewal of primary health care (PHC), and why now, more than ever? The immediate answer is the palpable demand for it from Member States - not just from health professionals, but from the political arena as well. Globalization is putting the social cohesion of many countries under stress, and health systems, as key constituents of the architecture of contemporary societies, are clearly not performing as well as they could and as they should. People are increasingly impatient with the inability of health services to deliver levels of national coverage that meet stated demands and changing needs, and with their failure to provide services in ways that correspond to their expectations. Few would disagree that health systems need to respond better - and faster - to the challenges of a changing world. PHC can do that. (p. 5)
Certainly with many countries' health systems under stress because of globalisation, options that utilise social cohesion of communities should form an important architecture for health delivery in contemporary African societies. Arguably, therefore, PHC as part of an integrated, robust and coherent community systemic structure provides an alternative approach to strengthening PHC delivery.

The Alma-Ata Declaration was therefore critical as a PHC movement that mobilised professionals and institutions, governments and civil society organisations, researchers and grassroots organisations that undertook to tackle the politically, socially and economically unacceptable health inequalities. The PHC movement calls for health systems that put people at the centre of health care. One observable weakness in many health delivery systems in Africa that is clearly contrary to PHC as outlined in the Alma-Ata Declaration is the dominance of curative health professionals and overt exclusion or fuzzy participation of communities in PHC. This cannot be further away from the values of the PHC movement. This weakness is also echoed by the World Health Report (WHO 2008:7). The report states that health systems are developing in directions that contribute little to equity and social justice and fail to get the best health outcomes for their money. There are clearly observable worrisome trends that indicate a departure from the AlmaAta Declaration. These are:

- health systems that focus disproportionately on a narrow offer of specialised curative care

- health systems where there is a command and control approach to disease control and focus on short-term results, which is fragmenting service delivery

- health systems where a hands-off or laissez-faire approach to governance has allowed unregulated commercialisation of health to flourish.

These developments in health provision indicate the need to reposition and refocus $\mathrm{PHC}$ in order to optimise health outcomes. The World Health Report (WHO 2008:9) insightfully compares how PHC has been implemented until recently and the required reforms (see Table 1).

The early efforts at implementing PHC indicate a cheap and low-level participation of communities, for instance, basic education on hygiene, water sanitation in the villages, volunteers and non-professional community workers, topdown driven services and low cost investment. However, the reforms entail realisation that PHC is not cheap and requires considerable investment. It entails coordination of comprehensive response at all levels. It promotes healthier lifestyles and mitigates potential health effects and environmental hazards. The reformed approach to PHC shows a revitalised and integral role of communities in PHC rather than an appendage role.

The Africa Health Strategy (2007-2015) indicated that people in many African countries are not empowered to meaningfully participate in health and this is compounded by cultural 
TABLE 1: The World Health Report. Early attempts at implementing PHC Extended access to a basic package of health interventions and essentia drugs for the rural poor.

Concentration on mother and child health.

Focus on a small number of selected diseases, primarily infectious and

acute.

Improvement of hygiene, water sanitation and health education at village level.

Simple technology for volunteer, non-professional community health workers.

Participation as the mobilisation of local resources and health centre management through local health management

Government-funded and-delivered services with a centralised top-down management.

Management of growing scarcity and downsizing.

Bilateral aid and technical assistance.

Primary care as the antithesis of the hospital.

$\mathrm{PHC}$ is cheap and requires only a modest investment.

\section{Current concerns of PHC reforms}

Transformation and regulation of existing health systems, aiming for universal access and social health protection. Dealing with the health of everyone in the community.

A comprehensive response to people's expectations and needs, spanning the range of risks and illnesses.

Promotion of healthier lifestyles and mitigation of the health effects of social and environmental hazards.

Teams of health workers facilitating access to and appropriate use of technology and medicines.

Institutionalised participation of civil society in policy dialogue and accountability mechanisms.

Pluralistic health systems operating in a globalised context.

Guiding the growth of resources for health towards universal coverage. Global solidarity and joint learning. Primary care as the coordinator of a comprehensive response at all levels. PHC is not cheap: it requires considerable investment, but it provides better value for money than its alternatives.

Source: WHO, 2008, Primary health care - Now more than ever, viewed 15 April 2016, from www.who.int/whr/2008/en/

$\mathrm{PHC}$, primary health care.

factors. Hence there is need to have a strong community involvement focus to ensure that people are aware of their role in health interventions. Primary health interventions should be implemented in a culturally sensitive manner. This calls for a strong community approach to avoid passive involvement and marginalisation of community members. Community members should participate in $\mathrm{PHC}$ rather than have it dominated by clinicians. There is need for a strategy that ensures meaningful health literacy through community empowerment for women and girls. The approach should be local context specific to effectively reach the poor.

Kirunga, Ogwal and Peter (2007) reported that health reforms in Uganda resulted in renewed focus on PHC. The WHO is supporting the Uganda government to reactivate the implementation of the PHC strategy (WHO 2014). The African Union argued that about $75 \%$ of diseases in Africa are preventable if there is increased community participation (New Vision 2008). Obioha and Molale (2011) from their study on the implementation of PHC in Lesotho observed that community participation in health is possible and implementable despite the real challenges of uncooperative community members if not properly coordinated. The WHO (1988) in a follow-up review and implementation guidelines after policy formulation by governments after the Alma-Ata commitment (1978) spelt out the implementation guidelines for effective PHC implementation that are still relevant today in Africa and other parts of the world. They outlined guidelines on implementation of PHC driven by community participation at district level. They emphasised community involvement in health through governance and education. Ramana Gandham, Chepkoech and Walelign (2013) in their Kenya review observed that despite renewed focus on PHC, the role of communities seems to be relegated to forming health care communities while the actual outreach is being done by community health workers, who are an extension of the Ministry of Health. In this case community participation is almost an addendum in health care. Community participation is very low or non-existent. The role of the community is only evident in providing accountability but not in real practical participation in health delivery. This is despite strong community structures such as FBOs (World Bank 2014). Babbel (2012) observed that by 2007, in Tanzania, PHC was identified as a means of accelerating health care services as FBOs such as churches play a critical role.

From the above discussion, the question that emerges is: what is the role and position as well as contribution of churches in PHC in Africa?

\section{Participation of churches (as community structures) in primary health care in Africa}

The role of churches in health care in Africa has been widely documented. Magezi (2012) and Zvobgo (1986) noted that there was widespread church-based health care in many African countries prior to the 1980s. This was largely provided without dependence on the state. For instance, the first rural hospital and successive ones in similar rural locations in Zimbabwe were started by churches - for example, Mt Selinda (1893), followed by Morgenster Mission (1894), Chikore (1900) and several others. Green et al. (2002) provided an insightful mapping of the leading role of churches in health care in Africa (Ghana, Kenya, Lesotho, Zimbabwe, Malawi, Tanzania and Uganda). A study by Laris et al. (2001) confirmed that women, youth, religious and traditional groups, termed 'local civil society organisations', undertook considerable health-development activities. Birdsall and Kelly (2005), in their study of organisations operating at grassroots community level in South Africa, observed that a significant number of the organisations were FBOs. Foster's (2010) study revealed a similar trend across many sub-Saharan African countries where congregations and religious support groups constitute the majority (63\%) of community-level organisations. The World Council of Churches (2010) reported that World Health Organization estimates that FBOs provide $30 \%-70 \%$ of health care in the developing world.

Babbel (2012) and Dambisya and Ichoku (2012), like many other researchers, noted that FBOs have been the major providers of health care in sub-Saharan Africa, particularly to underserved communities. Babbel (2012) observed that churches (FBOs) provided approximately half of health services in Tanzania at the time of its independence. This situation was also noted by Zvobgo (1986) in Zimbabwe, and many others such as Foster (2010). However, despite clear evidence of the church's participation in health as community and national institutions, there are gaps regarding understanding of the precise models used at grassroots level. Mati (2013) rightly noted that while FBOs are the most prominent manifestations of civil society in Africa that play a 
key role, there is inadequate attention given to FBOs in social scientific analysis.

Samuels et al. (2010) agreed with Mati (2013) that FBOs have not seriously been explored. They noted that this is partly because some humanitarian organisations do not value the role of FBOs that much. While Samuels et al. argued that the oversight of FBOs' importance is a result of the weak view of some humanitarian organisations; there are more reasons. The ambivalent role of FBOs should be noted. Mati (2013) observes that while FBOs have been instrumental in addressing the needs of community people, they have also been used by religious fundamentalists and extremists to the detriment of society. Some groups of people have used faith, say, to support gender-based violence and other forms of violence, such as the Boko Haram in Nigeria. There is also concern of a blurred line between development work by FBOs and proselytising people using the same resources. Notwithstanding these concerns about FBOs, Samuels et al. (2010) reported that there is evidence in many situations that FBOs provide a critical role in communities such as PHC.

The observable problems regarding the work of churches in PHC is the lack of clarity on the meaning and usage of the word church and churches in health care, church health models, unrealistic expectations and a lack of clarity on the contributions expected of churches. To clear the 'fuzziness', Magezi (2012) proposed the following typologies of the work of churches in health: government clad in church health care, church diakonia department and congregational ecology. The government clad in health care is about churches owning and running hospitals providing the same medical care services provided at government health care centres. There is no distinction between the church and the government. The church diakonia department refers to denominations with established health and development departments that are centrally controlled. The congregational ecology model refers to individual congregations responding to health care needs that organically arise in their context. The interventions arise out of community need. Because of its deep embeddedness in the local grassroots community, the congregational ecology model arguably provides a useful nexus for churches' contribution in PHC where community participation is critical. However, the challenge is to practically discern some models of bridging the church as a separate community institution connecting with the rest of the people in a community in a systematic way in PHC. James (2009) observed that churches' interventions tend to mostly benefit church members, which is contrary to true community development. In many instances, there is contrary evidence to the simplistic assumptions that churches play a neutral community development role in activities such as PHC. Therefore, it is critical to assess some practical church-driven programmes to determine the models of how churches are connecting with communities in primary health in an impartial way.

In view of the above discussion, a Salvation Army preventive PHC programme implemented in three countries in East
Africa, namely Kenya, Tanzania and Uganda, will accordingly be considered.

\section{Methodology - Description of the church-driven primary health care programme}

\section{Salvation Army health initiative}

The Salvation Army has played a major role in health delivery across the world for as long as it has existed. They have operated hospitals and clinics, amongst other things. The Salvation Army (n.d.) holds that medical services are effective, influential and sustainable if they are linked to community development where the Salvationists and other people participate. The Salvation Army works in 126 countries and has over 180 health programmes worldwide (The Salvation Army International, International Health Services n.d.). The Salvation Army encourages local communities to respond to health issues as well as increase capacity of communities to provide care in order to develop health communities.

In line with the overall vision of the Salvation Army, Salvation Army leaders in East Africa territories with support from the International Headquarters initiated a health flipcharts project to address some health challenges experienced in Kenya, Uganda and Tanzania. These challenges included diseases such as cough, chest infection, malaria, diarrhoea and many other preventable diseases. The flipcharts were informed by a set of health education resources developed by a team at International Health Services based on the UN/WHO resource 'Facts for Life'. The flipcharts provided current understanding on 10 health issues: HIV and/or AIDS, malaria, nutrition and growth, diarrhoea and hygiene, cough and chest infection, injury prevention, safe motherhood, immunisation, birth spacing and contraception and breastfeeding. The project was implemented in Kenya, Uganda and Tanzania. The programme was a church-based initiative where community facilitators were trained by Salvationist leaders. Training focused on health content and proper use of the charts to facilitate discussions on health issues as well as to encourage communities to take appropriate health action with the aim of ensuring that families stay healthier. The flipcharts were written in simple language with the aid of pictures. The charts provided a practical, effective, low-cost and low-tech way of protecting and promoting the development of healthy children and adults. Thus, the flipcharts provided lifesaving knowledge about good health practices in simple language and pictures.

The flipcharts health project was implemented through the usual Salvation Army church leadership system where there is no particular staff solely devoted to the management of the project like in NGOs. There was no financial provision to cover implementation costs. The church arm that was responsible for implementing the project was the Home League ${ }^{2}$ and

2.Home League/Home League Fellowship is a programme for all women, married or single, who are working or are at home. No age limit. It covers a fourfold programme of php/southern-africa/local-presence/territorial-headquarters/women-s-department). 
League of $\mathrm{Mercy}^{3}$ through the Salvation Army structures to reach communities.

\section{Project assessment (data collection and analysis)}

After two years, the project was assessed. The assessment was a cross sectional research design that fell within an interpretivist paradigm. In an interpretivist paradigm, the researcher describes and interprets phenomena in order to derive meaning from the situation. An interpretivist paradigm holds to a constructivist philosophical position whereby complexities of the sociocultural world are experienced, interpreted and understood in a particular context (Alzheimer 2009; Babbie \& Mouton 2003; Marshall \& Rossman 2006; Maxwell 2005). An interpretive paradigm aims to discover and describe. It is generally focused on extracting and interpreting the meaning of experience. The researcher enters the world of others and thereby attempts to achieve a holistic rather than a reductionist understanding of the programme as it relates to PHC and community development among poor people.

Data were obtained from two main sources. These were primary data gathered directly from field implementation sites and secondary data through project documents. Four methods were used to collect evaluation data. These are project documents review, interviews with project teams and beneficiaries, observations of flipcharts facilitation sessions and an electronic questionnaire. A total of 24 indepth interviews with key informants and 17 focus group discussions were held in the three countries. A total number of 456 people participated in the interview discussions in one way or the other.

Various approaches were used to analyse the collected data. The approaches were used in an integrative manner to gain comprehensive insight on the collected data. A deductive coding approach based on the PHC conceptual model was employed. The PHC conceptual model, which encompasses processes and beliefs about the ways in which health care is structured, encompasses primary care, disease prevention, health promotion, population health and community development within a holistic framework, with the aim of providing essential community-focused health care (Shoultz \& Hatcher 1978; Thomas-MacLean et al 2004; WHO 1978). Therefore, these categories were used for coding. This philosophy and framework for PHC is directly informed by the Alma-Ata Declaration and the general practice in PHC. The cornerstones of PHC that were employed are access, equity, essentiality, appropriate technology, multisectoral collaboration and community participation and empowerment (WHO 1978). The models of church and community linkage were developed using a grounded theory

3.The League of Mercy/Community Care Ministries is a Salvation Army Mercy ministry that began in 1892 in Canada and is made up of people of all ages whose mission is to engage in a caring ministry. The main objective of the League of Mercy is to respond to the spiritual and social needs of the community. The ministry is adapted accordin to the local siturion, the size of its membership and the skils of its members, and endeavours to follow Christ's injunction, Inasmuch as ye have done it unto one of the least of these my brethren, ye have done it unto me' (Matthew 25:40, AV) (http:// www.salvationarmy.org.za/index.php/about-us/salvation-army-ministries). approach based on the question of how the church members implemented health interventions to the community members who were non-church members. Thus, open questions focusing on how the churches linked with the rest of the community members who were non-church members were asked. An inductive coding approach was employed to understand the details of the aspects under each of the deductive codes (i.e. under the primary health conceptual model elements). Key informant responses were triangulated through focus group participant discussions as well as data contained in project documents. The major limitation of the study was that the majority of the beneficiaries (over 90\%) were Salvation Army soldiers (church members) who were uncomfortable of being critical of their own church ministry. Focus group discussions were held with Salvation Army staff involved in implementing the flipchart programme across the three countries.

\section{Results and discussion}

The results presented and discussed below are compressed; hence participants' direct quotations were limited in the interest of brevity.

\section{Health services rendered by the churches}

The WHO (1948) definition of health that has been used over the years defines health as a state of complete physical, mental and social well-being and not merely the absence of disease or infirmity. The various health interventions therefore aim to achieve the definition of health stated by the WHO. Good health services are those that deliver effective, safe, quality personal and non-personal health interventions to those who need them, when and where needed, with minimum waste of resources. Health services should be efficient, effective and accessible. While health services, particularly clinical services were provided by government health departments, a number of services were rendered by churches. Churches engaged in:

Basic treatment, disease prevention, health education and promotion and community health development. (Programme reports)

Below are illustrations of the services performed by churches through their church membership in community health. These services were reported by participants and reported in programme documents:

- Basic treatment: After training and obtaining resource materials on basic treatment of diseases such as diarrhoea, rural church women treated people in the community using oral solutions. This was particularly prevalent in very poor communities where health facilities like clinics were far away (about $10 \mathrm{~km}$ ) and inaccessible because of unmaintained roads.

- Disease prevention: Trained church members formed part of the community disease surveillance teams. Church members were trained to identify symptoms of common diseases and inform health facility staff if there was a suspected case of particular diseases. They were also 
involved in mobilising community people to immunise their children. This included partnering with health facilities to identify children who were not immunised.

- Health promotion: Church members through formal and informal church programmes and groupings were involved in health promotion. This included sharing health information to educate community members on symptoms of various diseases. They also focused on harm reduction in community spaces such as homesteads, schools and walkways to prevent injuries. They led in prevention of disease vectors such as mosquitos by clearing tall grasses and dirty water dams. Health education included food and nutrition. Families and community members were educated on balanced diet.

- Community health within a holistic framework: In a context where there are limited health care facilities, church leaders were trained to train their church members in order to share the information with the rest of the people in the community. However, because of the integrated nature of community needs, the church and community members developed integrated community care ministries where they focused on many other activities such as livelihoods and income, savings schemes and human rights education. These interventions resulted in community building (cohesive community).

The above health interventions that resulted in harm reduction, hygiene improvement and other positive health results were reported by community people experiencing the work of church members. A community beneficiary in Busulwa (Uganda) explained that:

'After learning and understanding about harm to children by church people, it became clear to me that the reason why my children were always burnt is because I cook in an open area. Now I have a closed kitchen and there are fewer injuries.' [Community Volunteer, Busulwa Uganda]

The following testimonies were given by project beneficiaries:

'I used not to understand much about family planning but with the community discussions conducted by church people I now know a lot. I am now going with my husband for family planning.' (Beneficiary: Musoto Corps community, Mbale Division, Uganda Territory)

'Before the project we didn't know much about balanced diet. But now we know that you need to balance what you feed your children starting with the local food you grow in your garden.' (Beneficiary: Koheli Corps community, Serengeti Division, Tanzania Territory)

'The people have learnt, understood and applied hygiene and other prevention measures of diseases such as malaria. I challenge you to visit our homes so that you can see how much we now know about hygiene.' (Beneficiary: Matioli Community Health Centre, Shigomere Division, Kenya West Territory)

'We are the source of information in the community. We learnt a lot of health issues from the church and we confidently share this in communities during our outreaches. We are very confident about our knowledge.' (Community volunteer: Maiani Corps community, Sultani Division, Kenya East Territory)
The reported increase in health knowledge resulted in some level of behaviour change. Church and community people embraced health practices across all the areas where the churches conducted activities. People were significantly sensitised and made to understand preventive practices. Misconceptions about some health matters, particularly HIV, were cleared up and positive health practices reinforced. A health worker at Musoto Corps community, Mbale Division, in Uganda Territory, reported that 'there is increased HIV testing by couples'. As noted above, PHC forms an integral part of a country's health system. As Vukic and Keddy (2002) noted:

the main focus of primary health care is the health of individuals, families and communities; it is equally concerned with addressing the overall social and economic development of communities, thereby targeting the social determinants of health. (p. 545)

The reformed approach to PHC advocates a revitalised and integral role of communities in PHC. Consistent with the Africa Health Strategy (2007-2015), evidence from church health interventions indicates that many diseases in Africa are preventable. However, community members should participate in PHC rather than have it dominated by clinicians. This is particularly urgent in hard-to-reach communities where churches are one of very few community structures present (Magezi 2012).

From the services and discussion above, the question that arises is: what church-driven primary health models could be discerned?

\section{Emerging church-driven primary health care models}

The role and contribution of churches in health care in Africa is not disputed. This role varies from establishing and managing large Christian hospitals to rural church community HIV information and malaria prevention. However, there seem to be a number of simplistic assumptions in church-driven health programmes. Firstly, there is a lack of distinction between the church as a distinct community organisation operating from a different form to health facilities. Churches primarily exist or at least are perceived to focus on spiritual nurturing. This is different from community health facilities, whose role and mandate is health care. Secondly, while churches are subsystems of communities that comprise membership from the communities they are located in, a church community (community of believers belonging to a congregation) is separate from the rest of the overall community. Thirdly, church leaders and members in communities are assumed to possess diverse technical skills to respond to various community issues, which is not the case in most cases. Fourthly, there is sometimes oversight on the ambivalent role of churches regarding health in communities. Some churches of African origin, usually called African Independent Churches, in many instances are opposed to Western medicine.

The challenge therefore is to practically identify some models of bridging the churches as a separate community institution 


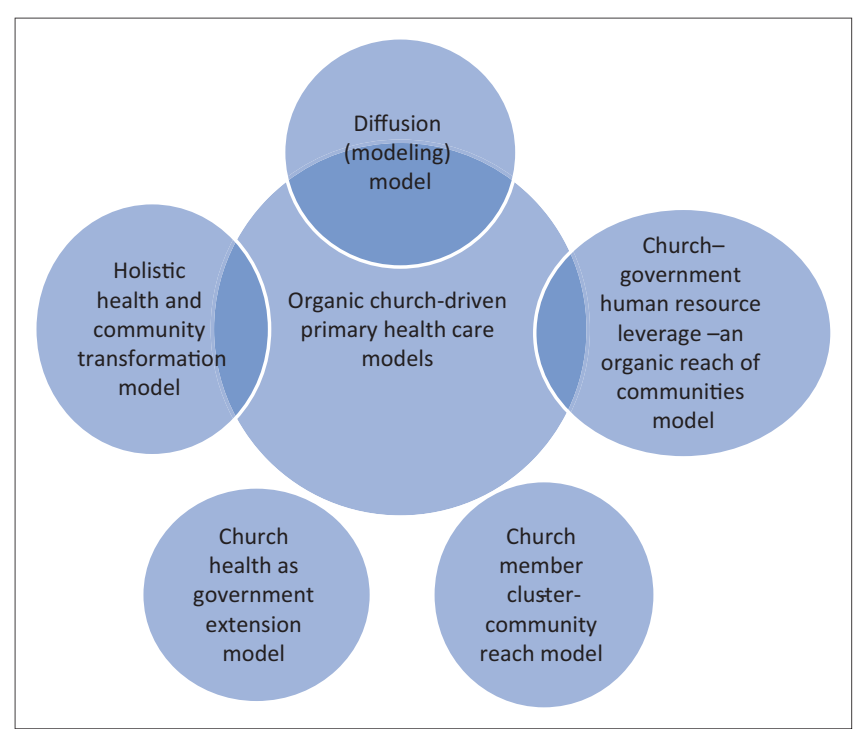

FIGURE 1: Organic church-driven primary health care models.

connecting with the rest of the people in the community in a systematic way in PHC. A criticism that has been raised against church-driven programmes is that church interventions tend to mostly benefit church members, which is contrary to true community development (James 2009). There is contrary evidence to the simplistic assumption that churches play a neutral community development role in activities such as PHC. Therefore, it is critical to determine some practical church-driven health programme models of how churches are connecting with communities in primary health in an impartial way. The typologies of churches' roles are clearly outlined by Magezi (2012). The typology that applies to this Salvation Army study is the congregational ecology. ${ }^{4}$ Figure 1 shows the emerging models as discerned from the study.

\section{Diffusion (modelling) model}

Diffusion is a transport process in environmental fluid mechanics (Karlsruher Institut für Technologie [KIT] 2009). It has two primary properties. It is random in nature and the transport is from regions of high concentration to low concentration with an equilibrium state of uniform concentration. In sociology, Crossman (2012:1) explains that social diffusion refers to 'a social process through which cultural knowledge, practices and materials spread from one social system to another'. Within the diffusion model, church members do not deliberately plan and develop church programmes that are run by the church members. Focus is on developing the capacity of church members in improving health aspects. As these people change their health behaviours and improve in health, the non-church community members also learn about health issues. The approach is ad hoc and based on "modelling health life". Community people see the example of the health lives of church members and copy it, as well as request assistance. The Kenya West focus group discussions (FGD) participants' response clearly explained this model: 'As Salvation Army members, people see how we live our lives. Our life shows an example of what cleanliness 4.Detailed discussion of the typologies is presented in Magezi (2012). and hygiene look like. Therefore people copy us to prevent diseases in their homes'.

The Salvation Army had a huge influence in the communities where it has a large number of members (Salvationists). Through flipchart health information, the Salvationists changed to adopt healthier ways of living. By living healthy lives, Salvationists modelled the basic preventive standards of a healthy life. Therefore, despite little or no sharing of health information, the wider community and other nearby churches learnt from the Salvation Army. The wider community learnt through this 'diffusion' of health practices. This approach also was evident in Kenya East, Kangundo Division at Kawethei, where Salvationists reported: 'Community people say to us (Salvationists) - we have very smart homes and we are copying how to live clean and healthy lives from you'.

\section{Church-government human resource leverage - An organic reach of communities model}

The church-government human resource leverage refers to the organic use of existing relevant human resources to effectively reach communities. This model draws from two realities of churches and church members in communities. Firstly, church members are community people with a community/family role. Secondly, church members possess different expertise and skills. A combination of community role and particular expertise provides some spontaneous responses, that is, an organic approach. It was observed that corps members (Salvationists) have different expertise and skills and they come from different backgrounds. For instance, some corps members are nurses, community headmen, etc. Therefore, the trained corps members' knowledge and skills were harnessed and used in their areas of strengths in communities. For instance, in Kenya East, Kenya West and Uganda, 'the majority of lead health programme facilitators are nurses already working with the Ministry of Health and yet they perform the role under the church health programme' (FGD respondents, Musoto at Mbali Division in Uganda). This created a strong link between the Salvation Army health project and government health ministries for project sustainability.

The strength of this approach is that the church health programme was integrated into corps (church) and community life spaces. The project was made part of ongoing community activities, which ensured wider reach. Furthermore, this strengthened the integrity of the health project and consequently the Salvation Army health programme. For instance, a Community Volunteer at in Musoto at Mbali Division in Uganda indicated:

\footnotetext{
'Because the flipcharts (project) contain very relevant information and are well written, I am invited to go and teach women in clinics using flipcharts. This is on top of my usual Community Health Worker role. The chart has penetrated everywhere and we use it in all community areas.' (Community Volunteer at in Musoto at Mbali Division in Uganda)
}

The weakness of this model, however, is that it was unstructured. It was driven by self-motivated and innovative individuals rather than a carefully thought through process. 


\section{Church member cluster - Community reach model}

This model entailed having the trained corps officers (church pastors) as trainers of trainers. They then shared the information with their church (corps) members. 'The church members formed clusters based on geographical convenience. After training at the corps (church), the health information charts were given to the clusters' (programme coordinator). Cluster members used the flipcharts to reach community members. The flipcharts were used as a facilitation tool and also as an information reference resource.

The strength of this model was that the health programme was not kept and privatised at the corps (church) office. The health information charts were accessible and constantly used as a reference resource. This also empowered corps members to confidently share health information in the community. Negatively, this approach reduced the lifespan of the health flipcharts, as they were sometimes poorly and unsafely kept in some homes. This approach also increased health information 'content inaccuracy', as some members were not adequately competent to respond to some questions asked.

\section{Church health activities as government extension model}

This model entailed having church health activities being conducted in an integrated way with the government Ministry of Health. A local health care centre in the community was the driver. Community meetings of different kinds were held at the centre. Church health volunteers reported to the clinic staff and church community outreach was conducted based on timetables and activities of the local clinic. Training of church volunteers was largely done by professional health staff at the centre. The activities were conducted in the format of the Ministry of Health prescribed by community health workers. The church health programmes therefore function as an extension of government health services.

\section{Holistic health and community transformation model}

This model entailed church members developing skills for people in the community for holistic, positive living. This included health information, rights awareness, farming, parenting, using the church as a space of information sharing and exchange on emerging issues and other community challenges. This was particularly the case in areas that were difficult to access, very poor and with no close-by health facility. It was evident that in the poor communities where the Salvation Army was operating, the health communication project created space for community people to meet, relate and strengthen relationships. In Uganda (Busulwa) the 'health flipcharts provided an opportunity and glue for people to participate in church activities' (Uganda Busulwa, Pastor). In Kitagutiti and Koheli (Tanzania) and Kawethei (Kenya East), 'the flipcharts provided a practical life dimension that strengthened members' togetherness' (Kenya East, Kawethei FGD discussion) as they applied lessons from the health flipcharts. Thus the health flipchart meetings and other projects implemented by the Salvation Army strengthened cohesion through implementing community interventions that addressed community needs.

\section{Integration and interrelatedness of the models}

The five models identified above to be emerging from the church-driven health interventions are not mutually exclusive. They are sometimes jointly applied. However, there is a clear distinction in their emphasis in different communities. While they mutually reinforce each other, they are clearly distinguishable. Notwithstanding that they emerged unintentionally, they indicate the reality of churches' practice in development initiatives in communities. They reflect the practical outworking of church interventions at grassroots level. However, on the one hand they demonstrate a general lack of conceptual clarity on church-driven community initiatives, while on the other hand they indicate the complexity of practically implementing community interventions.

Three of these models, namely diffusion (modelling), church-government human resource leverage and holistic health and community transformation, are largely unsystematic but systemic and $a d$ hoc. They are unplanned and emerge organically. However, the church member cluster community reach and church-driven health as government extension - is systematic. The former emerged organically, while the latter was influenced by community health delivery models of different Ministries of Health, particularly the community health worker approach. Thus the above models of health work of the Salvation Army clearly indicate PHC. Church communities' focus was central to the work, which is a key tenet of PHC. The programme prevented diseases, promoted health, enhanced population health and developed the community holistically as health work extended to other community issues. The programme increases access if implemented in an appropriate way.

\section{Conclusion}

The role of churches in PHC in poor contexts of Africa cannot be disputed. However, the challenge is the lack of clear models to measure the efficacy of the interventions. The interventions are also skewed towards health education and promotion. This paper has attempted to demonstrate the role of church-driven PHC using a practical case study of the health work of the Salvation Army in East Africa. It outlined the health services rendered by churches as represented by the Salvation Army. It also identified five models that emerged from the work of the Salvation Army on churches' role in delivering PHC. The paper revealed that viewed from a PHC perspective, churches in Africa play a critical role. The impact of this role was demonstrated by reported experiences of the church and community members on the situation before and after the Salvation Army's intervention. 


\section{Acknowledgements Competing interests}

The author declares that he has no financial or personal relationships which may have inappropriately influenced him in writing this article.

\section{References}

Africa Health Strategy: 2007-2015, viewed 05 September 2015, from www.nepad. org/system/.../AFRICA_HEALTH_STRATEGY(health).pdf

Alzheimer, 2009, The four main approaches - Types of research, viewed 08 Novembe 2016, from http://www.alzheimer-europe.org/Research/Understandingdementia-research/Types-of-research/The-four-main-approaches

Babbel, B.E., 2012, Evaluating equity in the provision of primary health care in Tanzania, Master of Public Policy Essay submitted to Oregon State University in partial fulfillment of Master of Public Policy Degree, viewed 05 April 2016, from https://ir.library.oregonstate.edu/xmlui/.../Babbel_MPPEssay.docx?

Babbie, E. \& Mouton, J., 2003, The practice of social research, Oxford University Press, Cape Town.

Birdsall, K. \& Kelly, K., 2005, Community responses to HIV/AIDS: An audit of AIDSrelated activity in three South African communities, Centre for AIDS Development Research \& Evaluation, Johannesburg.

Crossman, A., 2012, Diffusion, viewed 05 May 2016, from http://sociology.about.com/ od/D_Index/g/Diffusion.htm

Dambisya, Y.M. \& Ichoku, H.E., 2012, 'African triage: Assessing alternatives to health care privatisation south of the Sahara', in D. McDonald \& G. Ruiters (eds.) Alternatives to privatization public options for essential services in the global south, pp. 290-318, Routledge, New York.

Foster, G., 2010, Faith untapped: Linking community-level and sectoral health and HIV/ AIDS responses, The United States President's Emergency Plan for AIDS Relief, viewed 08 August 2016, from http://www.pepfar.gov/documents/organization/195614.pdf

Göran, G., n.d., 'Practical inquiry as action research and beyond', in 16th European Conference on Information Systems, viewed 01 September 2017, from https:// pdfs.semanticscholar.org/0b1f/3a43d914b654b49c3a0620f5e9aa30d44d67.pdf

Green, A., Shaw, J., Dimmock, F. \& Conn, C., 2002, 'A shared mission? Changing relationships between government and church health services in Africa' International Journal of Health Planning and Management 17, 333-353. https:// doi.org/10.1002/hpm.685

James, R., 2009, Faith-based organisational development (OD) with churches in Malawi, Praxis Note No. 47, International NGO Training and Research Centre, viewed 20 July 2016, from www.intrac.org/resources

Karlsruher Institut für Technologie (KIT), 2009, Concepts, definitions, and the diffusion equation, viewed 20 April 2016, from http://www.ifh.uni-karlsruhe.de/lehre/ envflu_i/Downloads/course script/ed2/ch1.PDF

Kirunga, C., Ogwal, T. \& Peter, O., 2007, Primary health care and health sector reform in Uganda, viewed 25 July 2016, from www.bioline.org.br/pdf?hp04006

Laris, P., Baum, F., Schaay, N., Sanders, D. \& Kahssay, H., 2001, Tapping in to civil society: Guidelines for linking health systems with civil society, The National Library of Australia Cataloguing-in-Publication entry: BNO 73089 2883, viewed 20 June 2001 from http://whqlibdoc.who.int/publications/2001/0730892883_eng.pdf

Magawa, R., 2012, Primary health care implementation: A brief review, viewed 05 August 2016, from http://www.consultancyafrica.com/index.php?option=com content\&view=article\&id=1096:primary-health-care-implementation-a-briefreview-\&catid=61: hiv-aids-discussion-papers\&Itemid=268

Magezi, V., 2007, HIV and AIDS, poverty and pastoral care and counselling: A homebased and congregational systems ministerial approach in Africa, Sun Media, Stellenbosch.

Magezi, V., 2012, 'From periphery to the centre: Towards repositioning churches for meaningful contribution to public health care', HTS Teologiese Studies/Theological Studies 68(2), Art. \#1312, 1-8. https://doi.org/10.4102/ hts.v68i2.1312

Magezi, V., 2017, 'Making community development at grassroots reality: Churchdriven development approach in Zimbabwe's context of severe poverty', In die Skriflig 51(1), a2263. https://doi.org/10.4102/ids. v51i1.2263

Marafa, B.F., n.d., Primary Health Care (PHC), viewed 05 August 2016, from http:// www.aiu.edu/publications/student/english/PRIMARY\%20HEALTH $\% 20$ CARE $\% 20$ (PHC).html

Marshall, C. \& Rossman, G.B., 2006, Designing qualitative research, 4th edn., Sage Thousand Oaks, CA.

Mati, J.M., 2013, 'Bringing back "Faith" in discourses of African civil society: Views from a Convening in Nairobi', in ISTR Africa Network Regional Conference, Nairobi, July $11-13$.
Maxwell, J.A., 2005, Qualitative research design: An interactive approach, 2nd edn., Sage, Thousand Oaks, CA

New Vision, 2008, 30 years of primary healthcare: Has Uganda made any progress? viewed 10 August 2016, from http://www.newvision.co.ug/D/8/26/651267

Obioha, E.E. \& Molale, M.G., 2011, 'Functioning and challenges of primary health care (PHC)', Ethno Medicine 5(2), 73-88. https://doi.org/10.1080/09735070.2011.118 86393

Peters, D.H., Taghreed, A., Olakunle, A., Akua, A.I. \& Nhan, T., 2014, 'Implementation research: What it is and how to do it', Journal of Sports Medicine 48, 731-736. https://doi.org/10.1136/bmj.f6753

Ramana Gandham, N.V., Chepkoech, R. \& Walelign, N., 2013, Improving universal primary health care by Kenya, UNICO studies series 5: A case study of the Health Sector Services Fund, The World Bank, Washington, DC.

Rodriguez-Garcia, R., Bonnel, R., Wilson, D. \& N'Jie N., 2013, Direction in development: Investing in communities achieves results - Findings from an evaluation of community responses to HIV and AIDS, World Bank, Washington, DC.

Ruger, P.J., 2014, 'The World Bank and global Health: Time for a renewed focus on health policy', Journal of Epidemiology and Community Health 68, 1-2. https:// doi.org/10.1136/jech-2013-203266

Samuels, F., Geibel, R. \& Perry, F., 2010, Collaboration between faith-based communities and humanitarian actors when responding to HIV in emergencies, Project Briefing, No 41, Overseas Development Institute, viewed 05 April 2016, froject Briefing, No 41, Overseas Developm
frodi.org/resources/docs/5902.pdf

Shoultz, J. \& Hatcher, P. 1997, 'Looking beyond primary care to primary health care: An approach to community-based action', Nursing Outlook 45(1), 23-26.

Stevenson, C., 2005, 'Practical inquiry/theory in nursing', Journal of Advanced Nursing 50, 196-203. https://doi.org/10.1111/j.1365-2648.2005.03379.x

Tarlier, D.S., Johnson, J.L. \& Whyte, N.B., 2003, 'Voices from the wilderness: An interpretive study describing the role and practice of outpost nurses', Canadian Journal of Public Health 94(3), 180-184.

The Salvation Army International, International Health Services, viewed 01 September 2015, http://www.salvationarmy.org/ihq/health

Thomas-MacLean, R., Tarlier, D., Ackroyd-Stolarz, S., Fortin, M. \& Stewart, M., 2004 , Tutor-PHC 2003/2004 research trainees 'no cookie-cutter response' conceptualizing primary health care, viewed 12 August 2015, from http://www.google.co.za/

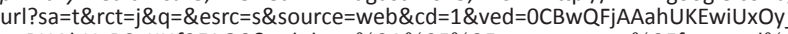
gqPHAhUsR9sKHf2FAO0\&url=http $\% 3 \mathrm{~A} \% 2 \mathrm{~F} \% 2 \mathrm{Fw}$ ww.uwo.ca $\% 2 \mathrm{Ffammed} \% \overline{2}$ Fcsfm $\% 2$ Ftutor-phc\%2Fdocumentation $\% 2$ Ftrainingpapers\%2FTUTOR Definitio_\%2520of_primar_\%2520health_care.pdf\&ei=dvXKVZSxLayO7Qb9i4Lō Dg\&usg=AFQjCNF2mHQdapUiBRJZ5NhYelrpLAuDRA\&sig2=3B2FS24u4gOC8FM5 Fn4jw\&bvm=bv.99804247, d.bGQ

University of Surrey, n.d., Introduction to research, viewed 08 November 2016, from http://libweb.surrey.ac.uk/library/skills/Introduction $\% 20$ to $\% 20$ Research $\% 20$ and $\% 20$ Managing $\% 20$ Information $\% 2$ Leicester/page 61 .htm

Vukic, A. \& Keddy, B., 2002, 'Northern nursing practice in a primary health care setting', Journal of Advanced Nursing 40(5), 542-548. https://doi. org/10.1046/j.1365-2648.2002.02411.x

WHO, 1948, WHO definition of health, viewed 15 July 2016, from http://www.euro. who.int/__data/assets/pdf_file/0003/152184/RD_Dastein_speech_ wellbeing_070̄Oct.pdf

WHO, 1978a, Declaration of Alma-Ata, WHO, Geneva.

WHO, 1978b, Primary health care, viewed 01 August 2016, from http://whqlibdoc. who.int/publications/1978/9241541288_eng.pdf

WHO, 1988, The challenge of implementation: District health systems for primary health care, Part A pp. 7-11 and Part C pp. 65-67, Geneva, viewed 12 May 2016, from www.ais.up.ac.za/med/pcm870/challenge.PDF

WHO, 2008, Primary health care - Now more than ever, viewed 15 April 2016, from www.who.int/whr/2008/en/

WHO, 2014, Primary health care, viewed 15 June 2016, from http://www.afro.who int/en/uganda/press-materials/item/1450-primary-health-care.html

Woolsey, K. \& Biebel, K., 2007, Implementation research: The black box of program implementation, viewed 01 September 2017, from https://www.umassmed.edu/ globalassets/center-for-mental-health-services-research/documents/productspublications/issue-briefs/rehab/

World Bank, 2014, Delivering primary health services in devolved health systems of Kenya: Challenges and opportunities, World Bank Group, Washington, DC, viewed 15 April 2016, from http://documents.worldbank.org/curated/ en/2014/09/20351566/delivering-primary-health-services-devolved-healthsystems-kenya-challenges-opportunities

World Council of Churches, 2010, Health system strengthening: Focus on church based pharmaceutical human resources, Contact Magazine no 189, January-March 2010, World Council of Churches, viewed 15 August 2016, from http://wcc-coe. org/wcc/news/contact.htm

Zvobgo, C.J., 1986, 'Medical missions: A neglected theme in Zimbabwe History, 1893-1897', Zambezia Xiii(ii), 109-118. 